\title{
Biomass fuels blamed for premature deaths in rural settings
}

Pollution is seen mostly as an urban problem, with mega cities spewing soot and fumes into the air. Twigs, leaves, dung and the countryside hardly fit that picture.

In millions of homes across rural Asia, Africa and Latin America, however, indoor air pollution caused by burning biomass and coal over primitive stoves is deadlier than outdoor pollution.

Indoor pollution causes roughly 1.6 million premature deaths each year, twice those caused by outdoor pollution, according to the World Health Organization. "Insidiously, it targets women and young children in the poorest households," says Kirk Smith, professor of public health at the

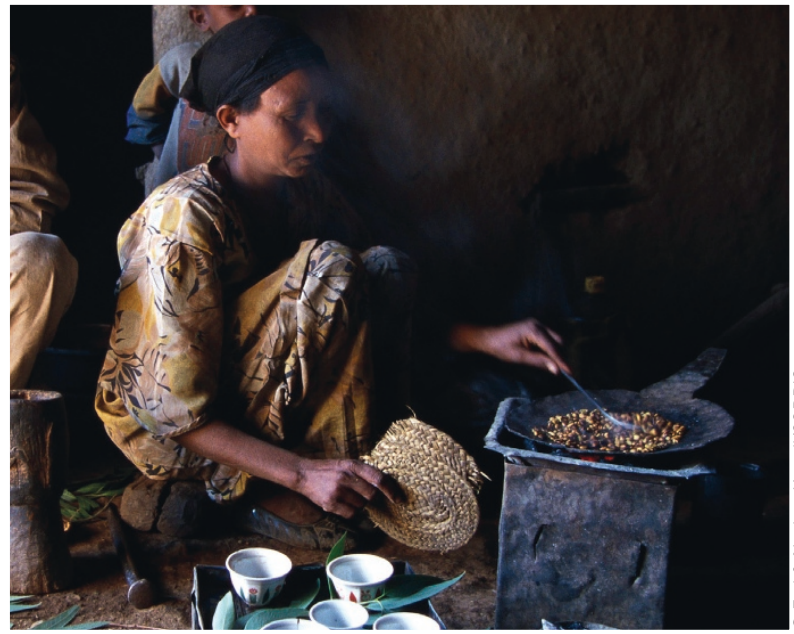

Burning problem: Popular in rural households, cheap biomass fuels cause deadly indoor pollution.

common effects. In China, the high incidence of lung cancer in women is linked to open coal stoves, says Smith. Tuberculosis, heart disease, blindness, cataract, immune and metabolic changes and still births also result.

The fuels do not burn completely, emitting polluting gases such as carbon monoxide, nitrogen dioxide, sulfur dioxide, the cancer-causing chemical benzopyrene and fine particles less than 10 microns in diameter that damage lung tissues.

A biomass Indian stove, for example, converts between $6 \%$ and $20 \%$ of the carbon into pollutants. Poor ventilation in homes traps the gases inside, compounding the problem.

Biomass fuels account for $80 \%$ of domestic energy consumption. "With

An estimated 3 billion people use biomass fuels to cook food and heat their homes worldwide, mainly because they cannot afford any other fuel. Biomass fuels account for nearly a tenth of the global energy consumed and their numbers are expected to rise substantially by 2030.
Although indoor pollution is ranked eighth as a risk factor for the global burden of disease by the World Health Organization (WHO), it ranks fourth in developing countries and third in India for the national disease burden.

Pneumonia in children and chronic lung disease in women are the most severe and

\section{British scientists find patent loophole}

Two British researchers say they have found a way to produce low-cost versions of expensive pharmaceuticals without breaking patent laws.

Sunil Shaunak and Steve Brocchini call their products "ethical pharmaceuticals."

Their first target is a naturally occurring molecule called interferon, which is used to treat hepatitis C. Commercial interferon has a coat of sugar molecules that reduces side effects and helps it last longer in the body. It is safe and effective, but also expensive.

In the UK, a full course of treatment costs around $\mathfrak{E} 7,000$, well beyond the means of most people in the developing world. Hepatitis C affects 200 million people and kills about half a million people each year.

The researchers attached sugar molecules to a different part of interferon, creating a configuration that may be novel enough to evade existing patents.

If it passes regulatory hurdles - and legal challenges - the compound would then be made affordable in the developing world. Patents on the process, along with the resulting interferon formulation, are held by PolyTherics Ltd., a company founded in 2001 by the researchers. Shantha Biotech, based in Hyderabad, India, has agreed to produce the drug, and the Indian government is set to conduct clinical trials.

Shaunak says other researchers should follow this example by reformulating other drugs. They have also partnered with the Drugs for Neglected Diseases Initiative to alter a leishmaniasis treatment. Drugs created by this method will need to be approved by regulatory agencies.

Pharmaceutical companies Roche and Schering-Plough, which hold patents on sugar-coated interferon, declined to comment. But Frederick Abbott, a Florida State University law professor and intellectual property expert, says the patents are sure to be contested.

"Are scientists morally and ethically justified in trying to develop workarounds to the patent system to provide treatment to more people? Absolutely," says Abbott. "But one shouldn't assume that industry is just going to accept that."

Brandon Keim, New York the Indian government's ban on cutting trees for fuel wood, many are using crop residues and dung that have worse combustion efficiencies than wood," says Twisha Lahiri, assistant director of Chittaranjan National Cancer Institute in Kolkata.

Lahiri's team has found evidence of genetic damage and, more recently, of blood platelets sticking together-a risk factor for blood clots -in women with chronic exposure to biomass smoke (Hum. Exp. Toxicol. 25, 627-635; 2006). The disease pattern is the same in outdoor and indoor pollution, but the impact is more severe in biomass users as they are more exposed to the fumes within their homes.

Preliminary data from a trial on 530 households in Guatemala shows that young children in households cooking with open wood fires also contract more severe forms of pneumonia, Smith reported at a December workshop in Indonesia on better air quality.

Fields where biomass wastes are burnt are equally damaging. For example, Brazil burns about 20 tons of sugar cane waste in fields each year. A Sao Paolo University study has found that the increase in fine polluting particles during the burning period correlates with a $21 \%$ rise in respiratory illnesses in children and a $31 \%$ increase in the elderly (Env. Health Persp. 114, 725-729; 2006).

Although evidence of the dangers is mounting, there is overall a lack of research interest in the subject, says Smith. "It took 17 years to get international funding for a health study after the first measurable evidence from India in 1981," he says. "Unfortunately poor people in rural areas do not have much clout."

T.V.Padma, New Delhi 